\title{
(甲)乙烯基化的叶绿素类二氢卟吩衍生物的合成及其光敏杀菌活性
}

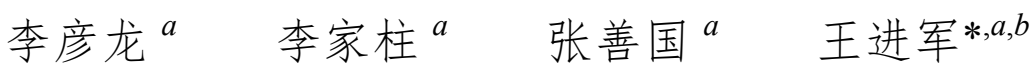 \\ (烟台大学化学化工学院 烟台 264005) \\ $\left(^{b}\right.$ 烟台大学文经学院食品与生物工程系 烟台 264005)
}

\begin{abstract}
摘要 以叶绿素-a(b) 的最初降解产物脱镁叶绿酸-a(b)甲酯为起始原料, 利用其二氢卟吩周环上的活性反应区域, 经羟 醛缩合、空气氧化和氧化剂氧化等常见的化学反应构建羟甲基或者甲酰基结构, 再通过 Grignard 反应、酸催化脱水和 E-环重排反应, 在周环的不同位置上引进了具有较高反应活性的甲烯基或者乙烯基, 完成了一系列未见报道的多端烯 基取代的叶绿素类二氢卟吩衍生物的合成, 其化学结构均经 UV、IR、 ${ }^{1} \mathrm{H} N M R$ 及元素分析予以证实; 对相应的化学反 应提出了可能的反应机理, 并对部分新化合物的体外光动力抗菌活性进行了测试.
\end{abstract}

关键词 叶绿素-a; 二氢卟吩; 化学修饰; 光敏杀菌; 合成

\section{Synthesis of (Methylenated)vinylated Chlorophyllous Chlorins and Study on Their Photosensitive Bactericidal Activities}

\author{
Li, Yanlong $^{a} \quad$ Li, Jiazhu $^{a} \quad$ Zhang, Shanguo $^{a} \quad$ Wang, Jinjun ${ }^{*, a, b}$ \\ ( ${ }^{a}$ College of Chemistry and Chemical Engineering, Yantai University, Yantai 264005) \\ $\left({ }^{b}\right.$ Department of Food \& Biological Engineering, Wenjing College, Yantai University, Yantai 264005)
}

\begin{abstract}
Pheophorbide-a and b methyl esters, as initial degraded products from chlorophyll-a and b, were used as starting materials, and the hydroxylmethylic or formylic structures were established making use of the active reaction regions on chlorin periphery by some common reactions, such as aldol condensation, allomerization, oxidant oxidation. The methylene or vinyl groups possessing higher reactivity were introduced at different site around chlorin pericycle by Grignard reavtion, acid-catalyzed dehydration and rearrangement reaction in E-ring. A series of unreported chlorophyllous chlorins substituted by multi-terminal alkenyl group were synthesized and their chemical structures were characterized by elemental analysis, UV, IR and ${ }^{1} \mathrm{H}$ NMR spectra. The in vitro photosensitive bactericidal activities of new chlorins were discussed and the possible mechanisms about corresponding reactions were tentatively proposed.
\end{abstract}

Keywords chlorophyll-a; chlorin; chemical modification; photosensitive bactericidal activity; synthesis

3-位乙烯基是众多叶绿素 (Chls) 和细菌叶绿素 (BChls) 的标识性结构, 也是影响这些天然产物自身性 质的关键性取代基团 ${ }^{[1 \sim 3]}$. 在天然属卟啉、二氢卟吩或 者细菌二氢卟吩的 $\pi$-共轭体系中, 3 -位乙烯基不仅能够 有效地延展四吡咯大环的最大可见光的吸收波长 $(\mathrm{Qy})$, 还可以广泛地形成各种典型的烯键反应而构建出特定 的化学结构. 例如, 叶绿素-a 的 3-位碳碳双键经四氧化 锇氧化成甲酰基而转化成叶绿素-d, 以卤化氢加成并水 解为羟乙基则形成细菌叶绿素 $-\mathrm{d}^{[4 \sim 6]}$. 除了用于叶绿素 类族中天然产物之间的转换以外, 3-位乙烯基的化学修
饰还可以键连和构建具有特殊属性的连带成分, 并已引 人关注地应用于光医学、超分子化学和分析化学等诸多 方面 ${ }^{[7,8]}$. 在叶绿素化学的理论和应用研究中, 叶绿素降 解产物周环上所形成的甲烯基结构同样表现出极为活 泼的反应活性, 并在新型叶绿素衍生物合成中受到人们 的关注 ${ }^{[9,10]}$. 探讨叶绿素降解产物的官能团引入和化学 结构修饰，是非对称性四吡咯大环化合物的合成及其应 用研究的重要基础工作. 叶绿素系列天然产物中的 3-位 乙烯基的特殊作用启示我们尝试新的合成策略，通过多 种常见的化学反应, 在四吡咯大环分子的不同位置上构

*E-mail: wjj1955@163.com

Received August 31, 2015; revised November 10, 2015 ; published online November 20, 2015

Project supported by the National Natural Science Foundations of China (No. 21272048) and the Project of Shandong Applied Resarch Centre of Gold Nanotechnology (2011).

国家自然科学基金(No. 21272048)和山东省黄金工程技术研究中心(2011 年度)资助项目. 
建具有较高反应活性的端位碳碳双键, 为有效合成具有 新颖结构和应用前景的叶绿素类二氢卟吩建立新的反 应位点.

本文以脱镁叶绿酸为起始原料, 利用其周环上的活 性反应区域实施化学修饰, 在不同的位置上引进甲烯基 或者乙烯基, 并对新形成的化合物进行官能转换, 完成 了一系列未见报道的多端烯基取代的叶绿素类二氢卟 吩衍生物的合成, 同时, 对部分新化合物的光敏杀菌活 性进行了测试.

在碘催化下, 脱镁叶绿酸-a 甲酯 (1a, MPa)和 $40 \%$ 的 甲醛水溶液发生亲核加成反应给出差向异构体混合物 2, 再于氢氧化钾甲醇溶液中开环脱水, 分离出 $15 \mathrm{a}$-甲 烯基二氢卟吩 $-\mathrm{e}_{6} 3(27 \%)$ 和少量开环成酯的二氢卟吩内 酯 $4(4 \%)$. 如果在氢氧化钠饱和的甲醇溶液中使得 $\mathrm{MPa}$ 与多聚甲醛反应, 则分别给出三个连有甲烯基的二氢卟 吩衍生物 $5(12 \%) 、 6(8 \%)$ 和 $7(26 \%)$. 选择脱镁叶绿酸$\mathrm{b}$ 甲酯 $(1 \mathrm{~b}, \mathrm{MPb})$ 与甲基溴化镁进行格氏反应，以 $56 \%$ 的 产率得到二氢卟吩醇酯 8 . 在对甲苯磺酸催化剂下, 于 甲苯中对其进行酸催化脱水, 但反应结果给出难于分离 的复杂混合物, 未获得以期在 7-位上形成碳碳双键的双 乙烯基取代的二氢卟吩 $\mathbf{8}^{\prime}$ (Scheme 1).

另一条合成路线起始于焦脱镁叶绿酸. 在碱性条件 下, 焦脱镁叶绿酸-a 甲酯(9a, MPPa) 与甲醛顺利地发生
羟醛缩合反应，并分离出 $38 \%$ 的二氢卟吩烯酮 $\mathbf{1 0}$, 再经 氢氧化锂促进与空气氧发生氧化作用，得到 12-甲酰基 取代的二氢卟吩醛 11 (21\%), 甲基溴化镁与其进行的格 氏反应选择性地发生在 12-位甲酰基上，直接脱水后分 离出含有三个端烯结构的二氢卟吩 12 (41\%); 而二氢卟 吩烯酮(10)与甲基溴化镁的格氏反应则只发生在 E-环的 酮羊基上, 以中等产率给出加成产物二氢卟吩二烯醇 $13(42 \%)$, 继续在甲苯中对其实施酸催化脱水, 同样由 于产物混杂的原因, 未获得期待的具有 1,3-丁二烯结构 的叶绿素衍生物 13'. MPPa (9a)的 3-位乙烯基经四氧化 锇和高碘酸钠的氧化形成甲酰基，直接与乙烯基溴化镁 的亲核加成则生成 $51 \%$ 的二氢卟吩醇 14 , 再选用四正 丙基过钌酸铵(TPAP)和 $N$-甲基吗啉 $N$-氧化物(NMMO) 混合氧化剂, 将其氧化成 $\mathrm{C}(3)$-烯丙酰基取代的二氢卟 吩二酮 15 (47\%). 二氢卟吩醛 $9 b$ 与甲基溴化镁的格氏 反应顺利地分离出 $57 \%$ 的二氢卟吩醇 16 , 进一步的酸 催化脱水则高产率转化成二氢卟吩二烯 $17(68 \%)$ (Scheme 2).

\section{1 结果与讨论}

\section{1 叶绿素降解产物周环上的甲烯或乙烯基的形成过 程}
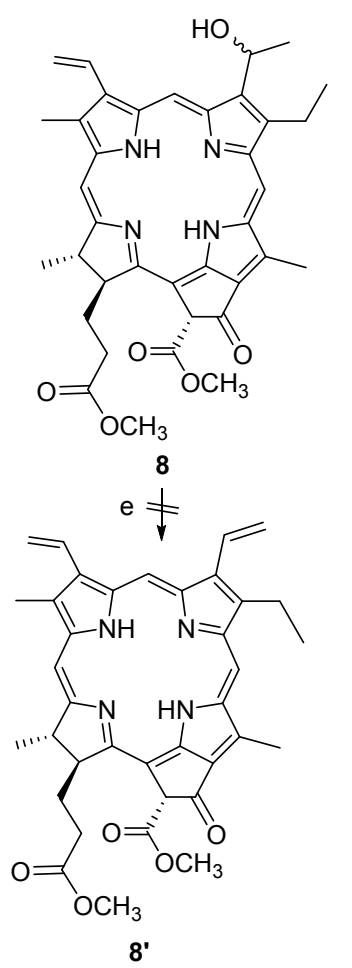
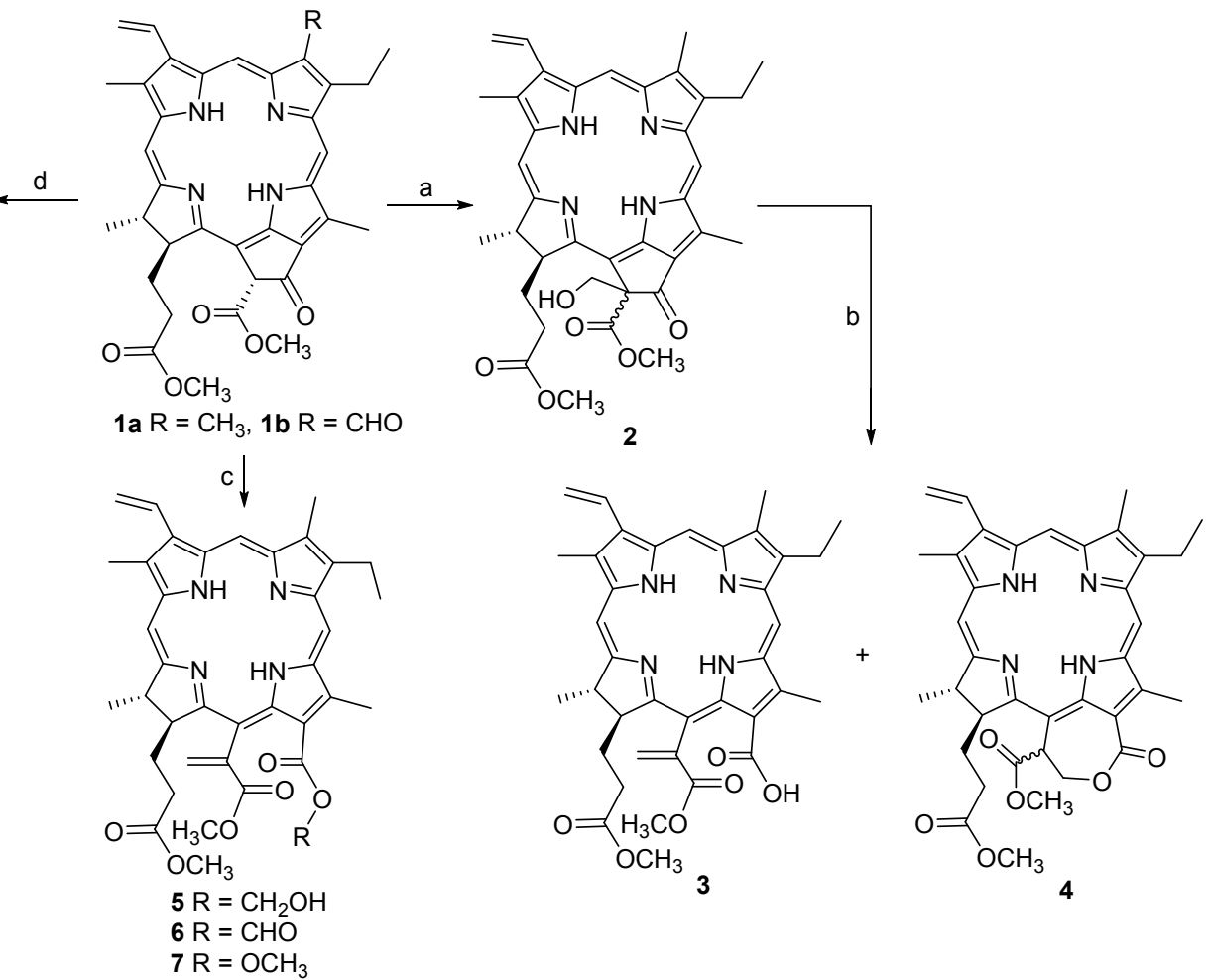

Reagents and conditions: (a) $40 \% \mathrm{CH}_{2} \mathrm{O} / \mathrm{CH}_{2} \mathrm{Cl}_{2} / \mathrm{I}_{2}$; (b) $\mathrm{NaOH} / \mathrm{MeOH}$; (c) $\mathrm{NaOH} / \mathrm{MeOH}\left(\mathrm{CH}_{2} \mathrm{O}\right)_{n}$; (d) $\mathrm{CH} \mathrm{H}_{3} \mathrm{MgBr} / \mathrm{THF}$; (e) TsOH/Toluene

图式 1 脱镁叶绿酸-a(b)的甲烯和乙烯基化

Scheme 1 The methylation and vinylation of pheophorbide-a(b) 

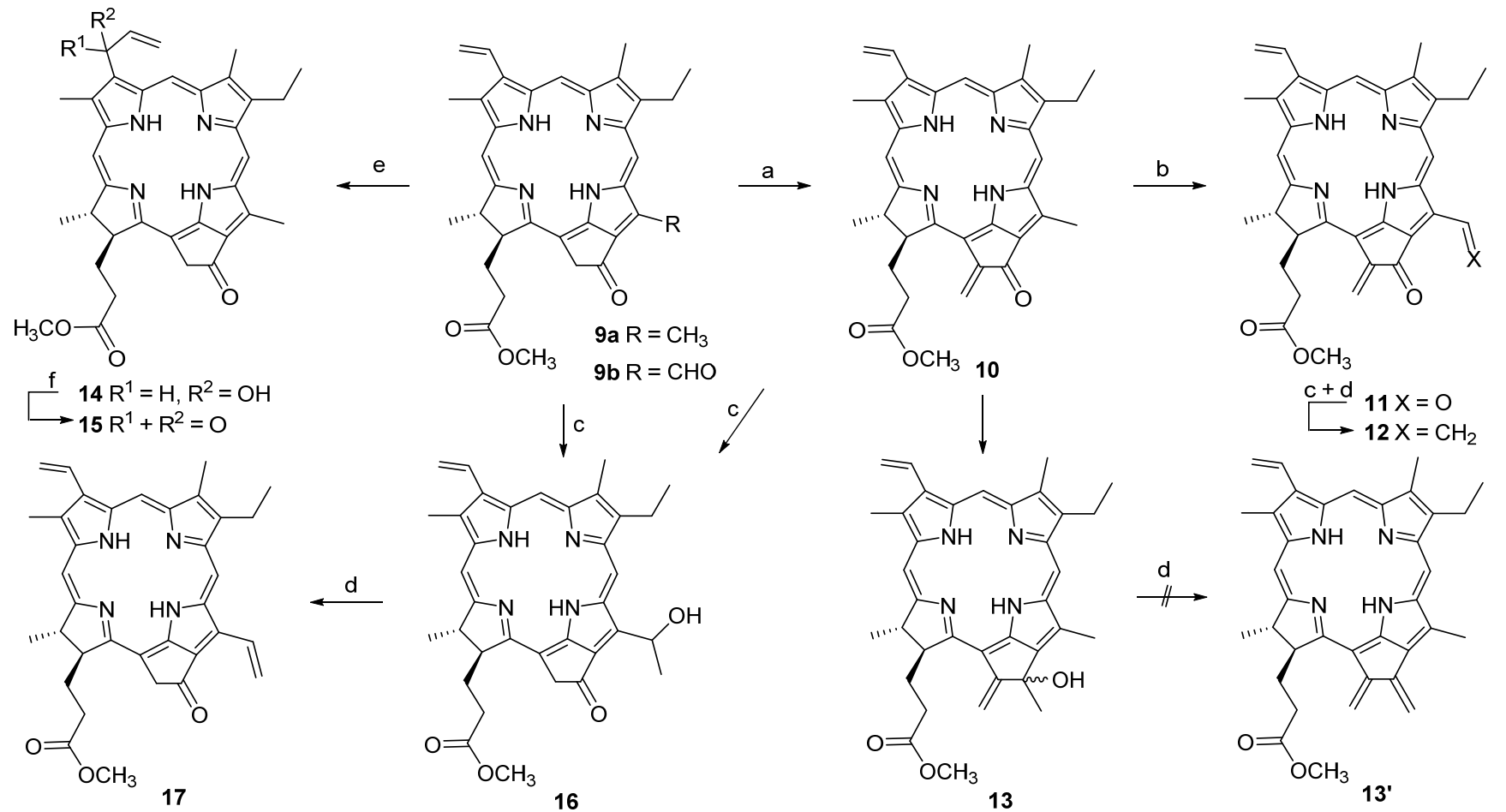

Reagents and conditions: (a) $\mathrm{NaOH} / \mathrm{MeOH} / 40 \% \mathrm{HCHO} / \mathrm{L}_{2}$; (b) $\mathrm{LiOH} / \mathrm{O}_{2} / \mathrm{THF} / \mathrm{MeOH}$; (c) $\mathrm{CH}_{3} \mathrm{MgBr} / \mathrm{THF}$; (d) TsOH/Toluene/90 ${ }^{\circ} \mathrm{C}$; (e) $\mathrm{OsO}_{4} / \mathrm{NaIO}_{4} / \mathrm{CH}_{2}=\mathrm{CHCH}_{2} \mathrm{MgBr}$; (f) $\mathrm{MMO} /\left(\mathrm{C}_{3} \mathrm{H}_{7}\right)_{4} \mathrm{NRuO}_{4}$

图式 2 焦脱镁叶绿酸-a 的甲烯和乙烯基化

Scheme 2 The methylation and vinylation of pyropheophorbide-a

$\mathrm{N}^{23}$ 轴向的两端, 即 A-子环和 C-子环所连带的化学结构. 外接 $\mathrm{E}$-环上的 $\alpha, \beta$-不饱和酮酯与甲醛很容易发生羟醛缩 合并生成 $13^{2}$-羟甲基脱镁叶绿酸 2 , 在碱性条件下水解 则形成亲核加成四面体 2'. 该中间体可以沿着两条途径 发生开环: 在 a-路线中, 失去氢氧负离子后于 $15 \mathrm{a}$-位上 形成碳碳双键给出二氢卟吩 3 ; 另一条路线 $\mathrm{b}$ 则首先形 成烯醇氧负离子 $\mathbf{A}$, 再经分子内质子交换转化成醇氧负 离子 $\mathbf{B}$, 然后发生分子内酯化并生成二氢卟吩内酯 4. 脱镁叶绿酸 1a 在与多聚甲醛反应的过程中同样可以生 成二氢卟吩酸 3 , 在有碱环境中形成羧氧负离子 $\mathbf{C}$, 继 续与多聚甲醛发生的亲核取代而给出二氢卟吩羟甲基 酯 6, 而后, 其 13-位上端位羟基失去质子并与甲醛发生 类坎尼查罗反应, 最终氧化成 C-子环上连有酸酐结构 二氢卟吩 7 (Scheme 3).

焦脱镁叶绿酸 9 在碱性环境中与甲醛也可以很顺利 地进行羟醛缩合, 所形成的反应产物 10 在外接环上构 建了烯酮结构. 由于 12-位甲基通过插烯结构与 E-环羰 基形成联系, 因此, 相应地显示出较强的 $\alpha$-氢反应活性. 首先, 在氢氧化锂促进下形成负碳离子 10 ' $\mathbf{a}$, 进而互变 异构成烯醇氧负离子 $10 ' \mathrm{~b}$, 接着与空气中的氧分子发生 作用生成氧化产物 11, 其 C(12)-甲酰基与甲基溴化镁的 格氏反应以及直接的酸催化脱水, 在 12-位上引进了一
个乙烯基，顺利地得到连有三个端烯的二氢卟吩 12 (Scheme 3).

烯酮 10 的 $13^{1}$-位酮羰基在冰浴中与甲基溴化镁可 以优先于 $\mathrm{C}(17)$-尾端酯基发生反应，其目的是期望格氏 产物 13 脱水后在外接环上形成一个丁二烯结构, 可能 因为设计产物 $13^{\prime}$ 的反应活性太强, 或者外接环张力过 大(其外接环上的 5 个碳原子都是以 $\mathrm{sp}^{2}$ 的杂化形式存 在), 所以，该反应得到非常复杂的混合产物; 当 3-位引 入甲酰基后，乙烯基溴化镁发生格氏反应选择性地发生 在 3a-位上，其外接环的酮羰基和 17-位的长链酯兼基对 反应均未参与反应, 然后经混合氧化剂氧化, 在 3-位上 构建了具有高反应活性的端位烯酮结构.

\section{2 (甲)乙烯化叶绿素类二氢卟吩的光敏杀菌活性}

光动力治疗 (Photodynamic therapy, PDT) 是通过光、 氧和光敏剂的组合作用而实施的一种非侵入性临床治 疗方法, 它利用光敏剂对生物组织的选择性光损伤而达 到治疗目的. 近年来, 卟啉类光敏剂的光动力抑菌研究 已经广泛地应用于治疗各种细菌感染疾病 ${ }^{[1]}$, 但有关深 度修饰的叶绿素降解产物的相应研究则鲜为报道. 因 此, 探讨新型叶绿素类二氢卟吩的光敏杀菌作用具有重 要的意义. 分别选择 $1 \mathrm{a} 、 3 、 5 、 7 、 10 \sim 13$ 和 17 为待测 化合物，以青霉素钠为对照品，在光照条件下，对金黄 


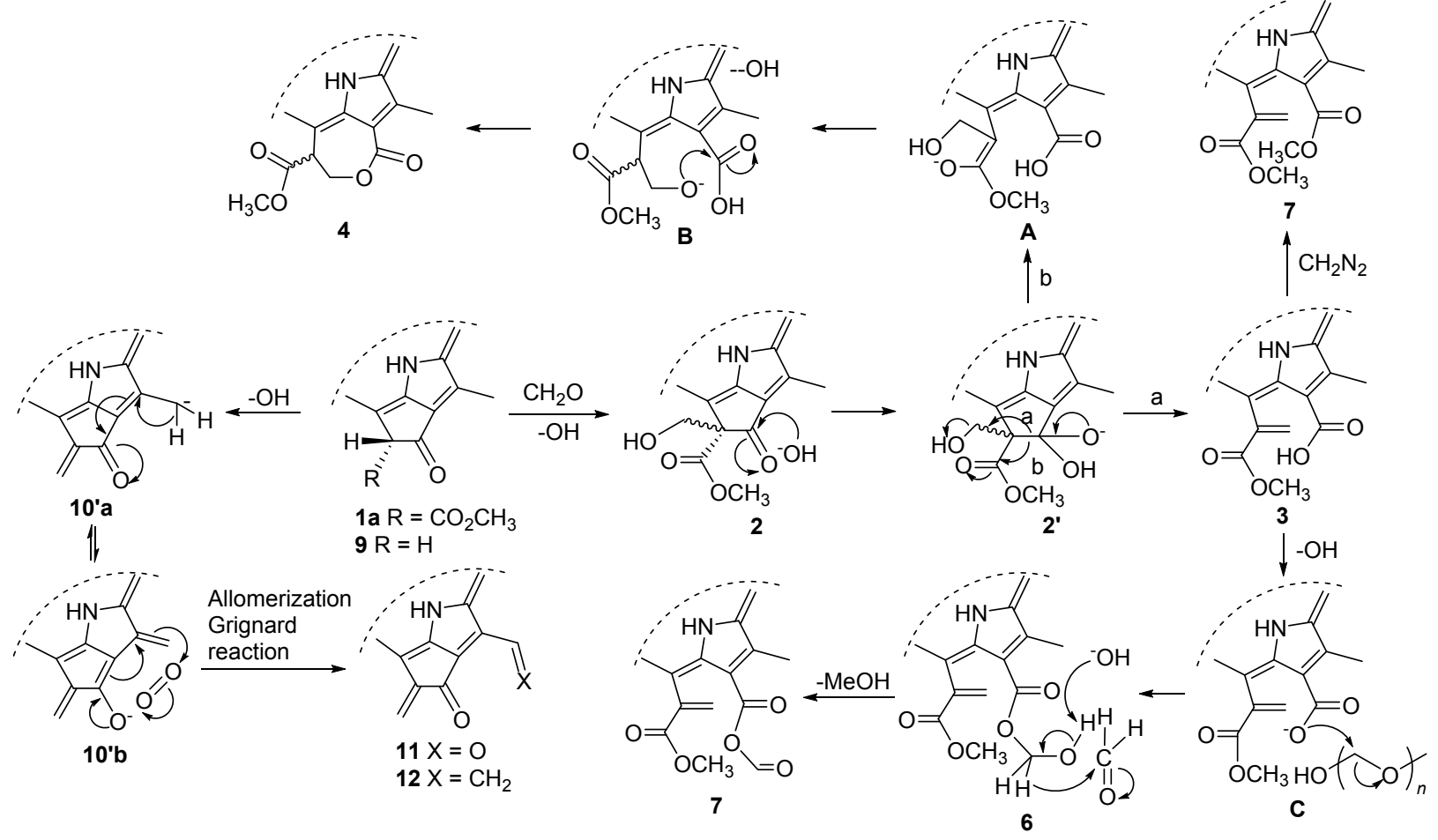

图式 3 焦脱镁叶绿酸-a 甲酯外接 E-环的空气氧化反应

Scheme 3 The allomerization of exocyclic E-ring on methyl pheophorbide-a

色葡萄球菌(Staphylococcus aureus ATCC 25922)和大肠 杆菌(Escherichia coli ATCC 25923)的光动力抑制作用进 行测定, 其测定结果如表 1 所示.

从表 1 可知, 所有测试的叶绿素类二氢卟吩对金黄 色葡萄球菌均表现出明显的杀灭作用, 但在相同条件下 对大肠杆菌的抑制效果相对较低. 以二氢卟吩醇 $\mathbf{3}$ 为例, 当其浓度为 $0.06 \mathrm{mmol} / \mathrm{L}$ 时对金黄色葡萄球菌就可达到 完全抑制的程度; 但在同等浓度下对大肠杆菌的杀灭能 力相对较弱, 直到其浓度增至 $0.24 \mathrm{mmol} / \mathrm{L}$, 对大肠杆 菌也没有形成完全杀灭. 其结果或可归因于大肠杆菌细 胞膜相对致密，其特定结构不仅限制了叶绿素类二氢卟 吩与细胞膜的结合，同时也阻断了单线态氧等活性质点 对细胞膜的破坏作用.

相对青霉素钠而言, 所有叶绿素二氢卟吩均表现出 更高的抗菌活性. 化合物 1a、7 和 11 对金黄色葡萄球菌
的杀灭能力相似，化合物 10、12 和 17 的光动力活性相 对较弱, 而在 C-D 环端向连有着基的叶绿素衍生物 3, 5 和 13 对相应的菌群则具有较强的光毒损伤作用. 例如, 当青霉素钠的浓度达到 $0.12 \mathrm{mmol} / \mathrm{L}$ 的时候, 其菌落数 才降至 500 以下; 而相同浓度的二氢卟吩醇却可以将菌 落数减少为零，完全抑制了金黄色葡萄球菌的生长. 二 氢卟吩醇 3,5 和 11 在浓度为 $0.06 \mathrm{mmol} / \mathrm{L}$ 时, 其菌落数 均已降为零. 二氢卟吩 11 和 12 的极性差别来自于 12位取代基的性质，其光敏杀菌能力也与其分子极性成正 比, 即二氢卟吩醛 11 的 PDT 活性远优于二乙烯基取代 的二氢卟吩二氢卟吩 12. 这些测试结果表明, 所连接的 取代基团的极性越高，其光动力抗菌活性越强.与此同 时，对相应的二氢卟吩也进行了非光照的对照实验，在 此条件下的叶绿素降解产物对金黄色葡萄球菌只产生 微弱的抑制作用，由此充分反映出该类四吡咯大环

表 1 光照下叶绿素类二氢卟吩对金黄色葡萄球菌(ATCC 25923)和大肠杆菌(ATCC 25922)的抑制作用

Table 1 The bactericidal activities of chlorophyllous chlorins on Staphylococcus aureus (ATCC 25923) and Escherichia coli (ATCC 25922) under photoirradiation

\begin{tabular}{|c|c|c|c|c|c|c|c|c|c|c|}
\hline \multirow{2}{*}{$\begin{array}{c}\text { 浓度/ } \\
\left(\mathrm{mmol} \cdot \mathrm{L}^{-1}\right)\end{array}$} & \multicolumn{10}{|c|}{ 菌落数(金黄色葡萄球菌/大肠杆菌) } \\
\hline & $1 \mathbf{a}$ & 3 & 5 & 7 & 10 & 11 & 12 & 13 & 17 & 青霉素钠 \\
\hline 0.01 & $520 / 2810$ & $470 / 2390$ & $440 / 2290$ & $525 / 2940$ & $680 / 3632$ & $515 / 2690$ & $790 / 2645$ & $465 / 2400$ & $630 / 3780$ & $4680 /-$ \\
\hline 0.02 & $240 / 2160$ & $190 / 1630$ & $185 / 1550$ & $260 / 2260$ & $430 / 2720$ & $225 / 2090$ & $335 / 2040$ & $200 / 1870$ & $400 / 3010$ & $4400 /-$ \\
\hline 0.03 & $90 / 1080$ & $66 / 860$ & $60 / 729$ & $105 / 1410$ & $210 / 1860$ & $82 / 1910$ & $185 / 1410$ & $72 / 1008$ & $230 / 1938$ & $2200 /-$ \\
\hline 0.06 & $6 / 180$ & $0 / 140$ & $0 / 120$ & $10 / 300$ & $40 / 810$ & $4 / 920$ & $82 / 215$ & $0 / 145$ & $66 / 1005$ & $1890 /-$ \\
\hline 0.12 & $0 / 100$ & $0 / 80$ & $0 / 76$ & $0 / 160$ & $0 / 612$ & $0 / 680$ & $0 / 160$ & $0 / 92$ & 0/720 & $490 /-$ \\
\hline 0.24 & $0 / 66$ & $0 / 22$ & $0 / 20$ & $0 / 98$ & $0 / 248$ & $0 / 286$ & $0 / 80$ & $0 / 34$ & $0 / 310$ & $260 /-$ \\
\hline
\end{tabular}


化合物具有高光毒性和低暗毒性的特殊性质, 符合作为 理想光敏剂所应具备的基本要求 ${ }^{[8]}$.

\section{2 结论}

利用叶绿素类二氢卟吩芳香性大环上的活性反应 区域, 通过羟醛缩合和氧化反应构建含氧官能结构, 再 通过 Grignard 反应、酸催化脱水和水解重排反应, 在周 环的不同位置上引进了具有较高反应活性的甲烯基或 者乙烯基, 完成了一系列未见报道的多端烯基取代的叶 绿素类二氢卟吩的合成; 相应的光敏抗菌实验表明, 叶 绿素类二氢卟吩具有良好的光动力生物活性. 沿着 $\mathrm{N}^{21}-\mathrm{N}^{23}$ 轴向建立具有端烯特征的碳碳双键, 不仅在叶 绿素二氢卟吩周环上建立了新的反应位点, 同时也能够 促成大环分子的其他性质产生规律性的变化, 为获取新 型四吡咯大环分子以及完善其物理、化学、生物等诸多 性质，提供了有效的切入手段和必要的理论依据.

\section{3 实验部分}

\section{1 仪器与试剂}

元素分析用 Perkin-Elmer 2400 型元素分析仪测定; IR 用 Perkin-Elmer 1730 型红外分光光度仪测定 $(\mathrm{KBr}$ 压 片); UV-Vis 用 UV-160A 型紫外分光光度计测定; ${ }^{1} \mathrm{H}$ NMR 用 Brucker ARX-400 型核磁共振仪测定, 内标 为 TMS. 所用试剂均为分析纯或化学纯. 脱镁叶绿酸-a 甲酯(1a)和焦脱镁叶绿酸-a 甲酯(9a)按文献[12]制备; 焦 脱镁叶绿酸-b 甲酯(1b)按文献[13]制备.

3.2 15a- 甲烯基二氢卟吩 $-e_{6}-13,17-$ 二甲酯 (3) 和 $15 a(R / S)$-二氢卟吩- $e_{6}-13,15 a-\varepsilon$-己内酯-1-单甲酯(4)的 合成

在 $30 \mathrm{~mL}$ 二氯甲烷中溶解 $487 \mathrm{mg} \mathrm{MPa}$ (1) (0.803 $\mathrm{mmol})$, 搅拌下先后加入 $3 \mathrm{~mL} 40 \%$ 的甲醛水溶液和 150 $\mathrm{mg}$ 碘, 室温搅拌 $8 \mathrm{~h}$ 后, 再加入 $20 \mathrm{~mL}$ 二氯甲烷和 40 $\mathrm{mL}$ 水, 分出有机相. 水相用二氯甲烷萃取 $(15 \mathrm{~mL} \times 2)$, 合并有机相并浓缩至干. 将所得化合物 2 的粗产物重新 溶解于 $25 \mathrm{~mL}$ 由氢氧化钠饱和的甲醇溶液, 用氮气充分 保护后室温搅拌 $1 \mathrm{~h}$. 将反应混合物倒入 $20 \mathrm{~mL}$ 水中, 用 稀硫酸调 $\mathrm{pH}$ 至 $2 \sim 3$, 加入 $70 \mathrm{~mL}$ 二氯甲烷后分出水层. 水层用二氯甲烷萃取 $(20 \mathrm{~mL} \times 3)$, 合并有机相, 用无水 硫酸钠干燥后减压除尽溶剂, 剩余物经硅胶柱层析分离 [洗脱剂: $V$ (乙酸乙酯) $: ~ V($ 石油醚 $)=1: 6$ ], 得到 $138 \mathrm{mg}$ 绿色固体 3 (0.217 mmol, 27\%)和 $21 \mathrm{mg}$ 绿色固体 4 (0.032 mmol, 4\%).

3: m.p. $234 \sim 237{ }^{\circ} \mathrm{C}$; UV-Vis $\left(\mathrm{CH}_{2} \mathrm{Cl}_{2}\right) \lambda_{\max }[\varepsilon /(\mathrm{L} \bullet$ $\left.\left.\mathrm{mol}^{-1} \cdot \mathrm{cm}^{-1}\right)\right]: \quad 420\left(8.98 \times 10^{4}\right), 518\left(7.64 \times 10^{3}\right), 546$ $\left(3.15 \times 10^{4}\right), 632\left(2.84 \times 10^{4}\right), 665\left(4.67 \times 10^{4}\right) \mathrm{nm} ;{ }^{1} \mathrm{H}$
NMR (400 MHz, $\left.\mathrm{CDCl}_{3}\right) \delta$ : -1.56 (br s, 1H, NH), 0.57 (br s, 1H, NH), 1.73 (t, $J=7.6 \mathrm{~Hz}, 3 \mathrm{H}, 8-\mathrm{CH}_{3}$ ), 1.87 (d, $\left.J=7.2 \mathrm{~Hz}, 3 \mathrm{H}, 18-\mathrm{CH}_{3}\right), 1.64 \sim 1.77(\mathrm{~m}, 1 \mathrm{H}, 17 \mathrm{a}+$ $17 \mathrm{~b}-\mathrm{H}), 1.86 \sim 1.96(\mathrm{~m}, 1 \mathrm{H}, 17 \mathrm{a}+17 \mathrm{~b}-\mathrm{H}), 2.09 \sim 2.18(\mathrm{~m}$, $1 \mathrm{H}, 17 \mathrm{a}+17 \mathrm{~b}-\mathrm{H}), 2.25 \sim 2.35(\mathrm{~m}, 1 \mathrm{H}, 17 \mathrm{a}+17 \mathrm{~b}-\mathrm{H}), 3.32$, $3.43,3.50,3.68,3.96$ (each s, each $3 \mathrm{H}, \mathrm{CH}_{3}+\mathrm{OCH}_{3}$ ), 3.78 (q, $J=7.6 \mathrm{~Hz}, 2 \mathrm{H}, 8 \mathrm{a}-\mathrm{H}), 4.21(\mathrm{~d}, J=7.6,2.2 \mathrm{~Hz}, 1 \mathrm{H}$, 17-H), 4.47 (dd, $J=17.0,7.2 \mathrm{~Hz}, 1 \mathrm{H}, 18-\mathrm{H}), 6.17$ (d, $J=$ $11.6 \mathrm{~Hz}, 1 \mathrm{H}$, cis-3b-H), 6.37 (d, $J=18.0 \mathrm{~Hz}, 1 \mathrm{H}$, trans-3b-H), 6.31 (s, 1H, 15a-methylene-H), $7.59(\mathrm{~s}, 1 \mathrm{H}$, 15a-methylene-H), 8.08 (dd, $J=18.0,11.6 \mathrm{~Hz}, 1 \mathrm{H}, 3 \mathrm{a}-\mathrm{H})$, $8.84,9.64,9.73$ (each s, each $1 \mathrm{H}$, meso-H); ${ }^{13} \mathrm{C}$ NMR (400 $\left.\mathrm{Hz}, \mathrm{CDCl}_{3}\right) \delta: 192.1,182.2,175.5,173.3,167.7,154.1$, $152.4,150.0,145.2,143.0,142.8,137.1,137.0,136.2$, $134.7,133.2,131.2,128.8,128.5,128.4,127.1,123.1$, $121.6,115.8,103.2,121.2,95.3,52.6,51.8,49.4,32.2$, $31.6,23.6,19.0,17.0,11.9,10.9$; IR (KBr) v: $3449(\mathrm{~N}-$ H), $2924(\mathrm{C}-\mathrm{H}), 1742,1708(\mathrm{C}=\mathrm{O}), 1686(\mathrm{C}=\mathrm{C}), 1560$ (chlorin skeleton), 1457, 1341, 1082, 1040, $971 \mathrm{~cm}^{-1}$; EI-MS $m / z$ : $637.5\left(\mathrm{M}+\mathrm{H}^{+}\right)$. Anal. calcd for $\mathrm{C}_{37} \mathrm{H}_{40} \mathrm{~N}_{4} \mathrm{O}_{6}$ : C 69.79, H 6.33, N 8.80; found C 69.66, H 6.24, N 8.98.

4: m.p. 205 $207{ }^{\circ} \mathrm{C}$; UV-Vis $\left(\mathrm{CH}_{2} \mathrm{Cl}_{2}\right) \lambda_{\max }[\varepsilon /(\mathrm{L} \bullet$ $\left.\left.\mathrm{mol}^{-1} \cdot \mathrm{cm}^{-1}\right)\right]: 418\left(9.13 \times 10^{4}\right), 509\left(7.57 \times 10^{3}\right), 558$ $\left(3.11 \times 10^{4}\right), 644\left(1.98 \times 10^{4}\right), 668\left(4.24 \times 10^{4}\right) \mathrm{nm} ;{ }^{1} \mathrm{H}$ NMR (400 MHz. $\left.\mathrm{CDCl}_{3}\right) \delta:-1.62(-1 / 58)($ br s, $1 \mathrm{H}$, $\mathrm{NH}), 0.43$ (br s, 1H, NH), 1.72 (1.71) (t, $J=7.6 \mathrm{~Hz}, 3 \mathrm{H}$, $\left.8-\mathrm{CH}_{3}\right), 1.97\left(\mathrm{~d}, J=7.2 \mathrm{~Hz}, 3 \mathrm{H}, 18-\mathrm{CH}_{3}\right), 2.17 \sim 2.33(\mathrm{~m}$, $1 \mathrm{H}, 17 \mathrm{a}+17 \mathrm{~b}-\mathrm{H}), 2.55 \sim 2.75(\mathrm{~m}, 2 \mathrm{H}, 17 \mathrm{a}+17 \mathrm{~b}-\mathrm{H})$, $2.79 \sim 3.03$ (m, 1H, 17a+17b-H), 3.26 (3.25), 3.30 (3.89), 3.60 (3.58), 3.71 (3.70) (each s, each $3 \mathrm{H}, \mathrm{CH}_{3}+\mathrm{OCH}_{3}$ ), $3.68 \sim 3.74$ (m, 2H, 8a-H), 4.47 (4.43) (q, $J=7.2 \mathrm{~Hz}, 1 \mathrm{H}$, 18-H), 4.47 (4.43) (dd, $J=9.2,1.8 \mathrm{~Hz}, 1 \mathrm{H}, 17-\mathrm{H}), 4.39$ $4.51\left(\mathrm{~m}, 2 \mathrm{H}, 15 \mathrm{a}-\mathrm{CH}_{2} \mathrm{O}\right), 5.55$ (5.45) (dd, $J=10.0,3.2 \mathrm{~Hz}$, $1 \mathrm{H}, 15 \mathrm{a}-\mathrm{H}), 6.21$ (dd, $J=11.6,1.2 \mathrm{~Hz}, 1 \mathrm{H}$, cis-3b-H), 6.31 (dd, $J=17.8,1.2 \mathrm{~Hz}, 1 \mathrm{H}$, trans $-3 \mathrm{~b}-\mathrm{H}), 8.01$ (dd, $J=17.8$, $11.6 \mathrm{~Hz}, 1 \mathrm{H}, 3 \mathrm{a}-\mathrm{H}), 8.60,9.41$ (9.39), 9.57 (9.55) (each s, each 1H, meso-H); IR (KBr) v: $3443(\mathrm{~N}-\mathrm{H}), 2832(\mathrm{C}-$ $\mathrm{H}), 1739,1688(\mathrm{C}=\mathrm{O}), 1653(\mathrm{C}=\mathrm{C}), 1527$ (chlorin skeleton), 1400, 1287, 1189, $793 \mathrm{~cm}^{-1}$; EI-MS m/z: 637.5 $\left(\mathrm{M}+\mathrm{H}^{+}\right)$. Anal. calcd for $\mathrm{C}_{37} \mathrm{H}_{40} \mathrm{~N}_{4} \mathrm{O}_{6}: \mathrm{C} 69.79, \mathrm{H} 6.33, \mathrm{~N}$ 8.80; found C 69.91, H 6.60, N 8.71.

3.3 15a-甲烯基二氢卟吩- $\mathrm{e}_{6}-13$-羟甲基酯-15, 17-二 甲酯(5)、15a-甲烯基二氢卟吩- $e_{6}-13$-甲酰基酯-15，17二甲酯(6)和 15a-甲烯基二氢卟吩- $\mathrm{e}_{6}$ 三甲酯(7)的合成

在 $10 \mathrm{~mL}$ 四氢呋喃中溶解 $686 \mathrm{mg} \mathrm{1a}$ (1.131 mmol) 
和 $120 \mathrm{mg}$ 研细的多聚甲醛, 在氮气充分保护下, 加入 $30 \mathrm{~mL}$ 由氢氧化钾饱和的甲醇溶液, 室温摚拌反应 $5 \mathrm{~h}$; 用浓盐酸调节 $\mathrm{pH}$ 值至 $2 \sim 3$, 先后加入 $200 \mathrm{~mL}$ 水和 100 $\mathrm{mL}$ 二氯甲烷分层, 分出有机相, 水相用二氯甲烷萃取 $(30 \mathrm{~mL} \times 2)$, 合并有机层, 水洗两次后用无水硫酸钠干 燥, 用重氮甲烷甲基化后除去溶剂, 剩余物经硅胶柱层 析分离 [洗脱剂: $V$ (乙酸乙酯) $: V($ 正己烷 $)=1: 6$ ], 得到 $91 \mathrm{mg}$ 绿色固体 $5(0.136 \mathrm{mmol}, 12 \%) 、 60 \mathrm{mg}$ 绿色固体 6 (0.091 mmol, 8\%)和 $191 \mathrm{mg}$ 绿色固体 $7(0.294 \mathrm{mmol}$, $26 \%)$.

5: m.p. $231 \sim 234{ }^{\circ} \mathrm{C}$; UV-Vis $\left(\mathrm{CHCl}_{3}\right) \lambda_{\max }[\varepsilon /(\mathrm{L} \bullet$ $\left.\left.\mathrm{mol}^{-1} \cdot \mathrm{cm}^{-1}\right)\right]: 423\left(6.43 \times 10^{4}\right), 519\left(4.32 \times 10^{3}\right), 546$ $\left(1.98 \times 10^{4}\right), 631\left(6.27 \times 10^{3}\right), 665\left(4.54 \times 10^{4}\right) \mathrm{nm} ;{ }^{1} \mathrm{H}$ NMR (400 MHz. $\left.\mathrm{CDCl}_{3}\right) \delta$ : $-1.56($ br s, $1 \mathrm{H}, \mathrm{NH}), 0.61$ (br s, $1 \mathrm{H}, \mathrm{NH}$ ), 1.73 (t, $J=7.6 \mathrm{~Hz}, 3 \mathrm{H}, 8-\mathrm{CH}_{3}$ ), 1.87 (d, $\left.J=7.2 \mathrm{~Hz}, 3 \mathrm{H}, 18-\mathrm{CH}_{3}\right), 1.60 \sim 1.71(\mathrm{~m}, 1 \mathrm{H}, 17 \mathrm{a}+$ 17b-H), $1.76 \sim 1.90(\mathrm{~m}, 1 \mathrm{H}, 17 \mathrm{a}+17 \mathrm{~b}-\mathrm{H}), 1.96 \sim 2.08(\mathrm{~m}$, $1 \mathrm{H}, 17 \mathrm{a}+17 \mathrm{~b}-\mathrm{H}), 2.14 \sim 2.36(\mathrm{~m}, 1 \mathrm{H}, 17 \mathrm{a}+17 \mathrm{~b}-\mathrm{H}), 3.29$, 3.38, 3.47, 3.61, 3.91 (each s, each $3 \mathrm{H}, \mathrm{CH}_{3}+\mathrm{OCH}_{3}$ ), 3.77 (q, $J=7.6 \mathrm{~Hz}, 2 \mathrm{H}, 8 \mathrm{a}-\mathrm{H}), 4.08$ (dd, $J=9.2,2.4 \mathrm{~Hz}, 1 \mathrm{H}$, $17-\mathrm{H}), 4.42(\mathrm{~d}, \quad J=7.2 \mathrm{~Hz}, 1 \mathrm{H}, 18-\mathrm{H}), 5.97(\mathrm{~d}, J=6.0$ $\left.\mathrm{Hz}, 2 \mathrm{H}, 13-\mathrm{CO}_{2} \mathrm{CH}_{2} \mathrm{OH}\right), 6.15(\mathrm{~d}, J=11.2 \mathrm{~Hz}, 1 \mathrm{H}$, cis-3b-H), 6.09 (s, 1H, 15a-methylene-H), 6.25 (d, $J=6.0$ $\left.\mathrm{Hz}, 2 \mathrm{H}, 13-\mathrm{CO}_{2} \mathrm{CH}_{2} \mathrm{OH}\right), 6.35(\mathrm{~d}, J=18.0 \mathrm{~Hz}, 1 \mathrm{H}$, trans-3b-H), 7.29 (s, 1H, 15a-methylene-H), 8.06 (dd, $J=$ 18.0, $11.2 \mathrm{~Hz}, 1 \mathrm{H}, 3 \mathrm{a}-\mathrm{H}$ ), 8.78, 9.60, 9.71 (each s, each $1 \mathrm{H}$, meso-H); ${ }^{13} \mathrm{C}$ NMR $\left(400 \mathrm{~Hz}, \mathrm{CDCl}_{3}\right) \delta: 195.9,173.4$, $170.2,169.0,154.7,152.1,150.3,148.6,144.4,139.6$, $138.8,136.9,134.2,131.6,129.8,126.1,106.6,103.3$, 99.0, 93.8, 52.0, 51.7, 49.6, 48.1, 31.0, 29.7, 19.9, 19.2, 17.2, 11.9, 10.8; IR (KBr) v: $3427(\mathrm{~N}-\mathrm{H}), 2925(\mathrm{C}-\mathrm{H})$, 1738, $1687(\mathrm{C}=\mathrm{O}), 1612(\mathrm{C}=\mathrm{C}), 1550$ (chlorin skeleton), 1450, 1329, 1242, 1175, 1016, $980 \mathrm{~cm}^{-1}$; EI-MS $\mathrm{m} / \mathrm{z}$ : $667.2\left(\mathrm{M}+\mathrm{H}^{+}\right)$. Anal. calcd for $\mathrm{C}_{38} \mathrm{H}_{42} \mathrm{~N}_{4} \mathrm{O}_{7}: \mathrm{C} 68.45, \mathrm{H}$ 6.35, N 8.40; found C 68.29, H 6.31, N 8.59;

6: m.p. $226 \sim 229{ }^{\circ} \mathrm{C}$; UV-Vis $\left(\mathrm{CHCl}_{3}\right) \lambda_{\max }[\varepsilon /(\mathrm{L} \bullet$ $\left.\mathrm{mol}^{-1} \cdot \mathrm{cm}^{-1}\right)$ ]: $422\left(6.65 \times 10^{4}\right), 522\left(4.25 \times 10^{3}\right), 544$ $\left(2.07 \times 10^{4}\right), 630\left(6.30 \times 10^{3}\right), 665\left(4.52 \times 10^{4}\right) \mathrm{nm} ;{ }^{1} \mathrm{H}$ $\operatorname{NMR}\left(400 \mathrm{MHz}, \mathrm{CDCl}_{3}\right) \delta$ : $-0.61($ br s, $1 \mathrm{H}, \mathrm{NH}), 0.60$ (br s, $1 \mathrm{H}, \mathrm{NH}), 1.70$ (t, $\left.J=7.6 \mathrm{~Hz}, 3 \mathrm{H}, 8-\mathrm{CH}_{3}\right), 1.83$ (d, $\left.J=6.8 \mathrm{~Hz}, 3 \mathrm{H}, 18-\mathrm{CH}_{3}\right), 1.62 \sim 1.75(\mathrm{~m}, 1 \mathrm{H}, 17 \mathrm{a}+$ $17 \mathrm{~b}-\mathrm{H}), 1.80 \sim 1.93(\mathrm{~m}, 1 \mathrm{H}, 17 \mathrm{a}+17 \mathrm{~b}-\mathrm{H}), 1.96 \sim 2.15(\mathrm{~m}$, $1 \mathrm{H}, 17 \mathrm{a}+17 \mathrm{~b}-\mathrm{H}), 2.30 \sim 2.42(\mathrm{~m}, 1 \mathrm{H}, 17 \mathrm{a}+17 \mathrm{~b}-\mathrm{H}), 3.24$, 3.40, 3.48, 3.64, 3.92 (each s, each $3 \mathrm{H}, \mathrm{CH}_{3}+\mathrm{OCH}_{3}$ ), 3.75 (q, $J=7.6 \mathrm{~Hz}, 2 \mathrm{H}, 8 \mathrm{a}-\mathrm{H}), 4.17$ (d, $J=7.6 \mathrm{~Hz}, 1 \mathrm{H}, 17-\mathrm{H})$,
4.44 (q, $J=6.8 \mathrm{~Hz}, 1 \mathrm{H}, 18-\mathrm{H}), 6.15$ (d, $J=11.2 \mathrm{~Hz}, 1 \mathrm{H}$, cis-3b-H), 6.36 (d, $J=17.8 \mathrm{~Hz}, 1 \mathrm{H}$, trans-3b-H), 8.08 (dd, $J=17.8,11.2 \mathrm{~Hz}, 1 \mathrm{H}, 3 \mathrm{a}-\mathrm{H}), 6.28$ (s, 1H, 15a-methyleneH), 7.56 (s, 1H, 15a-methylene-H), 7.87 (s, 13- $\mathrm{CO}_{2} \mathrm{CHO}$ ), 8.81, 9.63, 9.70 (each s, each 1H, meso-H); IR (KBr) v: $3434(\mathrm{~N}-\mathrm{H}), 2858(\mathrm{C}-\mathrm{H}), 1739,1689(\mathrm{C}=\mathrm{O}), 1623$ $(\mathrm{C}=\mathrm{C}), 1562$ (chlorin skeleton), 1460, 1343, 1218, 1160, 1027, $905 \mathrm{~cm}^{-1}$; EI-MS m/z: $665.4\left(\mathrm{M}+\mathrm{H}^{+}\right)$. Anal. calcd for $\mathrm{C}_{38} \mathrm{H}_{40} \mathrm{~N}_{4} \mathrm{O}_{7}$ : C 68.66, $\mathrm{H} \mathrm{6.07,} \mathrm{N} \mathrm{8.43;} \mathrm{found} \mathrm{C} \mathrm{68.79,}$ $\mathrm{H} 6.19, \mathrm{~N} 8.58$; 化合物 7 的分析数据与文献[14]一致.

\subsection{7-(1-羟乙基)-7-去甲酰基脱镁叶绿酸-b 甲酯(8)的 合成}

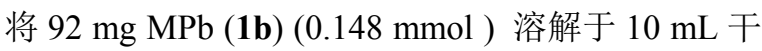
燥的四氢呋喃中, 氮气保护下于 $0{ }^{\circ} \mathrm{C}$ 搅拌缓慢滴加 0.3 $\mathrm{mL}$ 浓度为 $1 \mathrm{~mol} / \mathrm{L}$ 的甲基溴化镁乙梄溶液, 搅拌反应 5 $\min$, 向反应体系加入 $15 \mathrm{~mL}$ 冰水, 移去冰水浴并搅拌 $10 \mathrm{~min}$; 加入 $20 \mathrm{~mL}$ 二氯甲烷分层, 分出有机层, 水层 用二氯甲烷萃取 $(15 \mathrm{~mL} \times 2)$, 合并有机层, 用无水硫酸 钠干燥, 减压除去溶剂, 剩余物经硅胶柱层析分离[洗 脱剂: $V$ (乙酸乙酯) $: V$ (正己烷) $=1: 4]$, 得到 $88 \mathrm{mg}$ 黄 绿色固体 8 (0.083 mmol), 产率为 56\%. m.p. 251 $253{ }^{\circ} \mathrm{C}$; UV-Vis $\left(\mathrm{CHCl}_{3}\right) \lambda_{\max }\left[\varepsilon /\left(\mathrm{L} \cdot \mathrm{mol}^{-1} \cdot \mathrm{cm}^{-1}\right)\right]: 405$ $\left(1.21 \times 10^{5}\right), 510\left(4.84 \times 10^{3}\right), 541\left(1.21 \times 10^{4}\right), 607(8.47$ $\left.\times 10^{3}\right), 664\left(6.05 \times 10^{4}\right) \mathrm{nm} ;{ }^{1} \mathrm{H}$ NMR $\left(400 \mathrm{MHz}, \mathrm{CDCl}_{3}\right)$ $\delta:-1.69$ (br s, $1 \mathrm{H}, \mathrm{NH}), 0.37$ (br s, $1 \mathrm{H}, \mathrm{NH}), 1.70(1.76)$ (t, $\left.J=7.6 \mathrm{~Hz}, 3 \mathrm{H}, 8-\mathrm{CH}_{3}\right), 1.57(\mathrm{~d}, J=7.2 \mathrm{~Hz}, 3 \mathrm{H}$, 18- $\left.\mathrm{CH}_{3}\right), 2.17$ (2.19) (d, $\left.J=6.4 \mathrm{~Hz}, 3 \mathrm{H}, 7 \mathrm{a}-\mathrm{CH}_{3}\right), 1.97 \sim$ $2.32(\mathrm{~m}, 2 \mathrm{H}, 17 \mathrm{a}+17 \mathrm{~b}-\mathrm{H}), 2.44 \sim 2.65(\mathrm{~m}, 2 \mathrm{H}, 17 \mathrm{a}+$ 17b-H), 3.39 (3.37). 3.57 (3.56), 3.67, 3.89 (each s, each $\left.3 \mathrm{H}, \mathrm{CH}_{3}+\mathrm{OCH}_{3}\right), 3.58 \sim 3.70\left(\mathrm{~m}, 2 \mathrm{H}, 8 \mathrm{a}-\mathrm{CH}_{2}\right), 4.22(\mathrm{~d}$, $J=8.4 \mathrm{~Hz}, 1 \mathrm{H}, 17-\mathrm{H}$ ), 4.45 (q, $J=7.2 \mathrm{~Hz}, 1 \mathrm{H}, 18-\mathrm{H}), 6.18$ (d, $J=10.8 \mathrm{~Hz}, 1 \mathrm{H}, c i s-3 \mathrm{~b}-\mathrm{H}), 6.11 \sim 6.23(\mathrm{~m}, 1 \mathrm{H}, 7 \mathrm{a}-\mathrm{H})$, $6.24\left(\mathrm{~s}, 1 \mathrm{H}, 13^{2}-\mathrm{H}\right), 6.32(\mathrm{~d}, J=18.0 \mathrm{~Hz}, 1 \mathrm{H}$, trans-3b-H), 7.97 (dd, $J=18.0,10.8 \mathrm{~Hz}, 1 \mathrm{H}, 3 \mathrm{a}-\mathrm{H}), 8.81,9.63,9.70$ (each s, each $1 \mathrm{H}$, meso-H); ${ }^{13} \mathrm{C} \mathrm{NMR}\left(400 \mathrm{~Hz}, \mathrm{CDCl}_{3}\right) \delta$ : $203.1,173.5,171.3,161.3,156.7,148.9,145.1,141.5$, $137.8,136.0,131.0,129.6,128.3,126.4,122.5,109.1$, 104.8, 97.2, 93.1, 56.6, 51.7, 50.9, 50.1, 39.1, 31.2, 30.0, 25.8, 23.4, 19.4, 17.4, 12.1, 11.2; IR (KBr) v: $3409(\mathrm{~N}-$ H), $2960(\mathrm{C}-\mathrm{H}), 1726,1689(\mathrm{C}=\mathrm{O}), 1647(\mathrm{C}=\mathrm{C}), 1550$ (chlorin skeleton), 1460, 1380, 1271, 1205, 1143, 1070 $\mathrm{cm}^{-1}$; EI-MS $m / z$ : $637.6\left(\mathrm{M}+\mathrm{H}^{+}\right)$. Anal. calcd for $\mathrm{C}_{37} \mathrm{H}_{40} \mathrm{~N}_{4} \mathrm{O}_{6}:$ C 69.79, H 6.33, N 8.80; found C 69.61, H $6.48, \mathrm{~N} 8.78$. 


\section{$3.513^{2}$-甲烯基焦脱镁叶绿酸- $a$ 甲酯(10)的合成}

以 $\operatorname{MPPa}(\mathbf{9})$ 替代 MPa (1a), 按照制备化合物 2 的方 法合成, 得黄色固体 $\mathbf{1 0}$, 产率 $38 \%$. 物理常数与分析数 据与文献 $[10]$ 一致.

\subsection{2 -甲烯基-12-甲酰基-12-去甲基焦脱镁叶绿酸-a 甲酯(11)的合成}

在 $5 \mathrm{~mL}$ 水中溶解 $1.2 \mathrm{~g} \mathrm{LiOH}$, 再加入 $15 \mathrm{~mL}$ 甲醇 稀释, 然后倒入含有 $128 \mathrm{mg}$ 二氢卟吩烯酮 $\mathbf{1 0}$ (0.228 $\mathrm{mmol}$ )的 $25 \mathrm{~mL}$ 四氢呋喃中, 敞口剧烈搅拌 $3 \mathrm{~h}$ 后, 用 $25 \%$ 硫酸溶液调至 $\mathrm{pH}$ 为 $2 \sim 3$, 用二氯甲烷萃取(100 $\mathrm{mL} \times 3)$, 合并有机层后用无水硫酸钠干燥. 减压除去溶 剂, 重新溶解于 $25 \mathrm{~mL}$ 含有 $5 \%$ 硫酸的甲醇溶液中, 摚 拌过夜, 先后加入 $30 \mathrm{~mL}$ 水和 $45 \mathrm{~mL}$ 二氯甲烷, 分出有 机层, 水洗两次后用无水硫酸钠干燥, 减压除去溶剂, 剩余物经硅胶柱层析分离 [洗脱剂: $V$ (乙酸乙酯) : $V$ (正 己烷) $=1$ : 4], 得到 $28 \mathrm{mg}$ 黄绿色固体 11 (0.048 mmol), 产率 21\%. m.p. 229 232 ${ }^{\circ} \mathrm{C}$; UV-Vis $\left(\mathrm{CHCl}_{3}\right) \lambda_{\max }$

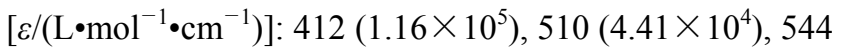
$\left(5.80 \times 10^{3}\right), 609\left(1.97 \times 10^{4}\right), 698\left(1.07 \times 10^{5}\right) \mathrm{nm} ;{ }^{1} \mathrm{H}$ NMR (400 MHz, $\left.\mathrm{CDCl}_{3}\right) \delta:-0.32$ (br s, $\left.1 \mathrm{H}, \mathrm{NH}\right), 0.56$ (br s, 1H, NH), 1.60 (t, J=7.6 Hz, 3H, 8- $\mathrm{CH}_{3}$ ), 1.79 (d, $\left.J=7.2 \mathrm{~Hz}, 3 \mathrm{H}, 18-\mathrm{CH}_{3}\right), 1.93 \sim 2.08(\mathrm{~m}, 1 \mathrm{H}, 17 \mathrm{a}+$ $17 \mathrm{~b}-\mathrm{H}), 2.36 \sim 2.44(\mathrm{~m}, 2 \mathrm{H}, 17 \mathrm{a}+17 \mathrm{~b}-\mathrm{H}), 2.62 \sim 2.71(\mathrm{~m}$, $1 \mathrm{H}, 17 \mathrm{a}+17 \mathrm{~b}-\mathrm{H}$ ), 3.03, 3.29, 3.69 (each s, each $3 \mathrm{H}, \mathrm{CH}_{3}$ $\left.+\mathrm{OCH}_{3}\right), 3.52(\mathrm{q}, J=7.6 \mathrm{~Hz}, 2 \mathrm{H}, 8 \mathrm{a}-\mathrm{H}), 4.44$ (d, $J=9.4$ $\mathrm{Hz}, 1 \mathrm{H}, 17-\mathrm{H}), 4.36$ (d, $J=7.2 \mathrm{~Hz}, 1 \mathrm{H}, 18-\mathrm{H}), 6.17$ (d, $J=$ $11.6 \mathrm{~Hz}, 1 \mathrm{H}$, cis-3b-H), 6.24 (d, $J=18.0 \mathrm{~Hz}, 1 \mathrm{H}$, trans-3b-H), $6.52\left(\mathrm{~s}, 1 \mathrm{H}, 13^{2}\right.$-methylene-H), $6.84(\mathrm{~s}, 1 \mathrm{H}$, $13^{2}$-methylene-H), 7.80 (dd, $\left.J=18.0,11.6 \mathrm{~Hz}, 1 \mathrm{H}, 3 \mathrm{a}-\mathrm{H}\right)$, 8.36, 8.91, 9.94 (each s, each 1H, meso-H), 11.38 (s, 1H, $\mathrm{CHO})$; IR (KBr) v: $3445(\mathrm{~N}-\mathrm{H}), 2925(\mathrm{C}-\mathrm{H}), 1742$, $1700(\mathrm{C}=\mathrm{O}), 1662(\mathrm{C}=\mathrm{C}), 1500$ (chlorin skeleton), 1347, 1259, 1093, 1021, $801 \mathrm{~cm}^{-1}$; EI-MS m/z: $575.6\left(\mathrm{M}+\mathrm{H}^{+}\right)$. Anal. calcd for $\mathrm{C}_{35} \mathrm{H}_{34} \mathrm{~N}_{4} \mathrm{O}_{4}$ : C 73.15, H 5.96, N 9.75; found C 73.31, H 6.02, N 9.87;

\section{$3.713^{2}$-甲烯基-12-乙烯基-12-去甲基焦脱镁叶绿酸-a 甲酯(12)的合成}

将 $92 \mathrm{mg}$ 二氢卟吩醛 $11(0.160 \mathrm{mmol})$ 溶解于 $10 \mathrm{~mL}$ 干燥的四氢呋喃中, 氮气保护下于 $0{ }^{\circ} \mathrm{C}$ 搅拌缓慢滴加 $0.3 \mathrm{~mL}$ 浓度为 $1 \mathrm{~mol} / \mathrm{L}$ 的甲基溴化镁乙醚溶液, 搅拌反 应 $5 \mathrm{~min}$, 然后再向反应体系加入 $15 \mathrm{~mL}$ 冰水和 $20 \mathrm{~mL}$ 二氯甲烷分层, 分出有机层浓缩至干, 重新溶解于 10 $\mathrm{mL}$ 含有 $10 \mathrm{mg}$ 对甲苯磺酸的干燥甲苯溶液中, $50{ }^{\circ} \mathrm{C}$ 搅 拌反应 $1 \mathrm{~h}$ 后加入 $15 \mathrm{~mL}$ 水, 分出有机相, 水相用二氯
甲烷萃取(15 mL×2), 合并有机层, 用无水硫酸钠干燥, 减压除去溶剂, 剩余物经硅胶柱层析分离[洗脱剂: $V($ 乙 酸乙酯) $: V$ (正己烷) $=1: 6]$, 得到 $38 \mathrm{mg}$ 绿色固体 12 (0.066 mmol), 产率为 $41 \%$. m.p. $211 \sim 214{ }^{\circ} \mathrm{C}$; UV-Vis

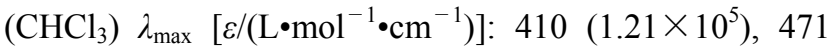
$\left(4.84 \times 10^{3}\right), \quad 503\left(1.21 \times 10^{4}\right), \quad 536 \quad\left(1.09 \times 10^{3}\right), \quad 607$ $\left(8.47 \times 10^{3}\right), 684\left(6.05 \times 10^{4}\right) \mathrm{nm} ;{ }^{1} \mathrm{H}$ NMR $(400 \mathrm{MHz}$, $\left.\mathrm{CDCl}_{3}\right) \delta:-1.38$ (br s, $\left.1 \mathrm{H}, \mathrm{NH}\right), 0.56$ (br s, $\left.1 \mathrm{H}, \mathrm{NH}\right)$, $1.67\left(\mathrm{t}, J=7.6 \mathrm{~Hz}, 3 \mathrm{H}, 8-\mathrm{CH}_{3}\right), 1.83(\mathrm{~d}, J=7.2 \mathrm{~Hz}, 3 \mathrm{H}$, $\left.18-\mathrm{CH}_{3}\right), 2.01 \sim 2.07(\mathrm{~m}, 1 \mathrm{H}, 17 \mathrm{a}+17 \mathrm{~b}-\mathrm{H}), 2.26 \sim 2.40$ $(\mathrm{m}, 2 \mathrm{H}, 17 \mathrm{a}+17 \mathrm{~b}-\mathrm{H}), 2.62 \sim 2.69(\mathrm{~m}, 1 \mathrm{H}, 17 \mathrm{a}+17 \mathrm{~b}-\mathrm{H})$, 3.18, 3.39, 3.66 (each s, each $\left.3 \mathrm{H}, \mathrm{CH}_{3}+\mathrm{OCH}_{3}\right), 3.62$ (q, $J=7.6 \mathrm{~Hz}, 2 \mathrm{H}, 8 \mathrm{a}-\mathrm{H}), 4.50$ (d, $J=7.2 \mathrm{~Hz}, 1 \mathrm{H}, 18-\mathrm{H}), 4.61$ (d, $J=9.2 \mathrm{~Hz}, 1 \mathrm{H}, 17-\mathrm{H}), 6.18$ (d, $J=11.6 \mathrm{~Hz}, 1 \mathrm{H}$, cis-3b-H), 6.24 (d, $J=11.6 \mathrm{~Hz}, 1 \mathrm{H}$, cis-12b-H), 6.28 (d, $J=18.0 \mathrm{~Hz}, 1 \mathrm{H}$, trans-3b-H), 6.54 (s, 1H, $13^{2}$-methylene$\mathrm{H}), 6.86\left(\mathrm{~s}, 1 \mathrm{H}, 13^{2}\right.$-methylene-H), 7.78 (d, $J=16.0,11.6$ $\mathrm{Hz}, 1 \mathrm{H}, 12 \mathrm{a}-\mathrm{H}), 7.96$ (dd, $J=18.0,11.6 \mathrm{~Hz}, 1 \mathrm{H}, 3 \mathrm{a}-\mathrm{H})$, 8.26 (dd, $J=17.6,11.6 \mathrm{~Hz}, 1 \mathrm{H}, 12 \mathrm{a}-\mathrm{H}), 8.59,9.31,9.59$ (each s, each 1H, meso-H); IR (KBr) v: $3443(\mathrm{~N}-\mathrm{H}), 2951$ $(\mathrm{C}-\mathrm{H}), 1734,1688(\mathrm{C}=\mathrm{O}), 1651,1637(\mathrm{C}=\mathrm{C}), 1560$ (chlorin skeleton), 1528, 1434, 1079, $904 \mathrm{~cm}^{-1}$; EI-MS $m / z: 573.3\left(\mathrm{M}+\mathrm{H}^{+}\right)$. Anal. calcd for $\mathrm{C}_{36} \mathrm{H}_{36} \mathrm{~N}_{4} \mathrm{O}_{3}: \mathrm{C} 75.50$, $\mathrm{H}$ 6.34, N 9.78; found C 75.61, H 6.44, N 9.68.

\section{$3.813^{1}(R / S)-13^{2}$-甲烯基-13 ${ }^{1}$-羟基- $13^{1}$-甲基- $13^{1}$-去氧 焦脱镁叶绿酸-a 甲酯(13)的合成}

以二氢卟吩烯酮 10 替代 MPb (1b), 按照制备化合 物 8 的方法合成. 得黄色固体 13, 产率 42\%. m.p. 246 $249^{\circ} \mathrm{C}$; UV-Vis $\left(\mathrm{CHCl}_{3}\right) \lambda_{\max }\left[\varepsilon /\left(\mathrm{L} \cdot \mathrm{mol}^{-1} \cdot \mathrm{cm}^{-1}\right)\right]: 410$ $\left(1.01 \times 10^{5}\right), \quad 511 \quad\left(1.27 \times 10^{4}\right), \quad 542 \quad\left(1.12 \times 10^{3}\right), \quad 607$ $\left(7.39 \times 10^{3}\right), 664\left(5.96 \times 10^{4}\right) \mathrm{nm} ;{ }^{1} \mathrm{H}$ NMR $(400 \mathrm{MHz}$, $\left.\mathrm{CDCl}_{3}\right) \delta:-2.89(-2.74)($ br s, $1 \mathrm{H}, \mathrm{NH}),-1.45$ (br s, $1 \mathrm{H}, \mathrm{NH}), 1.73$ (t, $\left.J=7.6 \mathrm{~Hz}, 3 \mathrm{H}, 8-\mathrm{CH}_{3}\right), 1.89$ (d, 3H, $J=$ $\left.7.2 \mathrm{~Hz}, 3 \mathrm{H}, 18-\mathrm{CH}_{3}\right), 1.96 \sim 2.17(\mathrm{~m}, 1 \mathrm{H}, 17 \mathrm{a}+17 \mathrm{~b}-\mathrm{H})$, $2.27 \sim 2.37(\mathrm{~m}, 1 \mathrm{H}, 17 \mathrm{a}+17 \mathrm{~b}-\mathrm{H}), 2.60 \sim 2.83(\mathrm{~m}, 2 \mathrm{H}$, $17 \mathrm{a}+17 \mathrm{~b}-\mathrm{H}), 2.25(2.12)\left(\mathrm{s}, 3 \mathrm{H}, 13^{1}-\mathrm{CH}_{3}\right), 3.36,3.61$, 3.54 (3.53), 3.61 (each s, each $\left.3 \mathrm{H}, \mathrm{CH}_{3}+\mathrm{OCH}_{3}\right), 3.80$ (q, $\left.J=7.6 \mathrm{~Hz}, 8 \mathrm{a}-\mathrm{CH}_{2}\right), 4.64$ (q, $\left.J=7.2 \mathrm{~Hz}, 1 \mathrm{H}, 18-\mathrm{H}\right), 4.75$ $(\mathrm{d}, J=8.8 \mathrm{~Hz}, 1 \mathrm{H}, 17-\mathrm{H}), 6.18$ (6.24) (s, 1H, 13 ${ }^{2}-$ methylene-H), 6.43 (6.48) (s, 1H, $13^{2}$-methylene-H), 6.15 (6.32) (d, $J=11.6 \mathrm{~Hz}, 1 \mathrm{H}$, cis-12b-H), 6.28 (6.33) (d, $J=$ $17.8 \mathrm{~Hz}, 1 \mathrm{H}$, trans-3b-H), 8.19 (8.17) (dd, $J=17.8,11.6$ Hz, 1H, 3a-H), 8.94 (8.92), 9.61 (9.63), 9.83 (9.79) (each s, each 1H, meso-H); IR (KBr) v: $3448(\mathrm{~N}-\mathrm{H}), 2915(\mathrm{C}-$ $\mathrm{H}), 1732,1686(\mathrm{C}=\mathrm{O}), 1614(\mathrm{C}=\mathrm{C}), 1550$ (chlorin skel- 
eton), 1496, 1360, 1220, 1166, 1110, $977 \mathrm{~cm}^{-1}$; EI-MS $m / z: 577.4\left(\mathrm{M}+\mathrm{H}^{+}\right)$. Anal. calcd for $\mathrm{C}_{36} \mathrm{H}_{40} \mathrm{~N}_{4} \mathrm{O}_{3}$ : C 74.97, H 6.99, N 9.71; found C 75.11, H 6.84, N 9.59.

\subsection{3-(1-羟烯丙基)-3-去乙烯基焦脱镁叶绿酸-a 甲酯 (14)的合成}

将 $352 \mathrm{mg}$ MPPa (9a) (0.642 mmol)溶解在 $15 \mathrm{~mL}$ 四 氢呋喃中, 加入 $0.5 \mathrm{~mL}$ 吡啶, 冷却到 $0{ }^{\circ} \mathrm{C}$, 剧烈搅拌条 件下加入含有 $180 \mathrm{mg}(0.678 \mathrm{mmol})$ 四氧化锇的 $8 \mathrm{~mL}$ 四 氢呋喃溶液, 混合液在 $0{ }^{\circ} \mathrm{C}$ 下搅拌反应 $30 \mathrm{~min}$, 然后室 温搅拌 $2 \mathrm{~h}$ 后, 加入过量的在 $50 \%$ 甲醇水溶液中饱和的 $\mathrm{NaHSO}_{3}$ 溶液, 继续摚拌 $40 \mathrm{~min}$, 过滤, 先后向滤液加入 $40 \mathrm{~mL}$ 二氯甲烷和 $40 \mathrm{~mL}$ 水, 有机相干燥后减压浓缩. 将浓缩物溶解于 $30 \mathrm{~mL}$ 甲醇中; 同时将 $400 \mathrm{~g}$ (1.868 $\mathrm{mmol}) \mathrm{NaIO}_{4}$ 溶解于 $20 \mathrm{~mL}$ 水中, 再加入 $1 \mathrm{~g}$ 硅胶. 然后 将两者合并, 反应体系的颜色迅速由墨绿色变为红棕 色, $30 \mathrm{~min}$ 后反应完毕, 加入 $150 \mathrm{~mL}$ 水和 $180 \mathrm{~mL}$ 二氯 甲烷, 过滤, 分出有机层, 干燥, 减压除溶剂, 用一短硅 胶层析柱分离出暗红色色带, 除去溶剂后溶解于 $25 \mathrm{~mL}$ 干燥的四氢呋喃中, 氮气保护下于 $0{ }^{\circ} \mathrm{C}$ 搅拌缓慢滴加 $0.3 \mathrm{~mL}$ 浓度为 $1 \mathrm{~mol} / \mathrm{L}$ 的烯丙基澳化镁乙醚溶液, 搅拌 反应 $5 \mathrm{~min}$ 后, 向反应体系加入 $25 \mathrm{~mL}$ 饱和氯化铵溶液, 移去冰水浴并摚拌 $10 \mathrm{~min}$; 再加入 $20 \mathrm{~mL}$ 二氯甲烷, 分 出有机层, 水相用二氯甲烷萃取 $(15 \mathrm{~mL} \times 2)$, 合并有机 层, 用无水硫酸钠干燥, 减压除去溶剂, 剩余物经硅胶 柱层析分离 [洗脱剂: $V$ (乙酸乙酯) $: V($ 正己烷 $)=1: 6$ ], 得到 $189 \mathrm{mg}$ 绿色固体 $\mathbf{1 4}(0.327 \mathrm{mmol})$, 产率为 $51 \%$. m.p. $247 \sim 250{ }^{\circ} \mathrm{C}$; UV-Vis $\left(\mathrm{CHCl}_{3}\right) \lambda_{\max }\left[\varepsilon /\left(\mathrm{L}^{\circ} \mathrm{mol}^{-1}\right.\right.$ • $\left.\mathrm{cm}^{-1}\right)$ ]: $395\left(1.21 \times 10^{5}\right), 497\left(4.84 \times 10^{3}\right), 516(1.09 \times$ $\left.10^{3}\right), 595\left(1.21 \times 10^{4}\right), 648\left(3.05 \times 10^{4}\right) \mathrm{nm} ;{ }^{1} \mathrm{H}$ NMR $(400$ $\left.\mathrm{MHz}, \mathrm{CDCl}_{3}\right) \delta:-3.30$ (br s, $\left.1 \mathrm{H}, \mathrm{NH}\right),-1.47(\mathrm{br} \mathrm{s}, 1 \mathrm{H}$, $\mathrm{NH}), 1.73$ (t, $\left.J=7.6 \mathrm{~Hz}, 3 \mathrm{H}, 8-\mathrm{CH}_{3}\right), 1.77$ (d, $J=7.2 \mathrm{~Hz}$, $\left.3 \mathrm{H}, 18-\mathrm{CH}_{3}\right), 2.02 \sim 2.39(\mathrm{~m}, 2 \mathrm{H}, 17 \mathrm{a}+17 \mathrm{~b}-\mathrm{H}), 2.40 \sim$ $2.78(\mathrm{~m}, 2 \mathrm{H}, 17 \mathrm{a}+17 \mathrm{~b}-\mathrm{H}), 3.30,3.46,3.52$ (3.51), 3.56 (each s, each $3 \mathrm{H}, \mathrm{CH}_{3}+\mathrm{OCH}_{3}$ ), 3.73 (q, $J=7.6 \mathrm{~Hz}, 2 \mathrm{H}$, $\left.8 \mathrm{a}-\mathrm{CH}_{2}\right), 4.36 \sim 4.62(\mathrm{~m}, 2 \mathrm{H}, 17-\mathrm{H}+18-\mathrm{H}), 4.96$ (d, $J=$ $\left.15.6 \mathrm{~Hz}, 1 \mathrm{H}, 13^{2}-\mathrm{H}\right), 5.06\left(\mathrm{~d}, J=15.6 \mathrm{~Hz}, 1 \mathrm{H}, 13^{2}-\mathrm{H}\right), 5.36$ (d, $J=10.2 \mathrm{~Hz}, 1 \mathrm{H}$, cis-3c-H), 5.64 (d, $J=16.8 \mathrm{~Hz}, 1 \mathrm{H}$, trans-3c-H), $6.60 \sim 6.70(\mathrm{~m}, 1 \mathrm{H}, 3 \mathrm{~b}-\mathrm{H}), 6.71 \sim 7.79(\mathrm{~m}$, 1H, 3a-H), 8.78, 9.60, 9.95 (9.94) (each s, each 1H, meso-H); ${ }^{13} \mathrm{C}$ NMR $\left(400 \mathrm{~Hz}, \mathrm{CDCl}_{3}\right) \delta: 198.2,173.6$, $168.4,156.3,153.1,150.6,144.2,141.9,138.8,137.9$, $136.2,135.6,135.0,134.5,133.2,132.2,130.2,129.5$, $129.3,128.6,128.5,128.0,126.9,121.9,110.2,101.4$, 99.9, 97.9, 93.1, 55.9, 52.9, 51.6, 51.3, 49.6, 37.4, 30.5, 28.7, 23.8, 19.5, 17.5, 12.2, 11.9, 11.3; IR (KBr) $v: 3407$
$(\mathrm{N}-\mathrm{H}), 2915,2847(\mathrm{C}-\mathrm{H}), 1736,1696 \quad(\mathrm{C}=\mathrm{O}), 1665$ (=C), 1520 (chlorin skeleton), 1384, 1303, 1168, 1066, $983 \mathrm{~cm}^{-1}$; EI-MS m/z: $579.4\left(\mathrm{M}+\mathrm{H}^{+}\right)$. Anal. calcd for $\mathrm{C}_{35} \mathrm{H}_{38} \mathrm{~N}_{4} \mathrm{O}_{4}$ : C 72.64, H 6.62, N 9.68; found C 72.57, H 6.54, N 9.89 .

\subsection{3 -烯丙酰基-3-去乙烯基焦脱镁叶绿酸-a 甲酯 (15)的合成}

在 $25 \mathrm{~mL}$ 的干燥二氯甲烷中溶解 $139 \mathrm{mg}$ 二氢卟吩 醇 $14(0.240 \mathrm{mmol})$, 在氮气保护下迅速加入 $20 \mathrm{mg} N$-甲 基吗啉氧化物并避光搅拌 $15 \mathrm{~min}$, 再小量分批加入 30 $\mathrm{mg}$ 高钓酸四丙基铵(TPAP), 约搅拌 $1.5 \mathrm{~h}$ 后反应结束, 再加入 $10 \%$ 的乙酸溶液搅拌反应 $1 \mathrm{~h}$, 静置过夜后分出 水层, 水层用二氯甲烷萃取 $(15 \mathrm{~mL} \times 3)$, 合并有机层并 用无水硫酸钠干燥, 除去溶剂, 剩余物经硅胶柱层析分 离 [洗脱剂: $V$ (乙酸乙酯) $: V($ 正己烷 $)=1: 4$ ], 得到 65 $\mathrm{mg}$ 绿色固体 15 (0.113 mmol), 产率为 47\%. m.p. 206

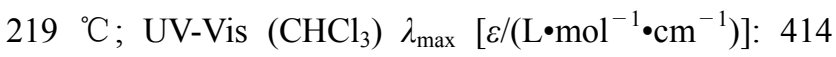
$\left(1.07 \times 10^{5}\right), 514\left(3.28 \times 10^{3}\right), 543\left(1.17 \times 10^{4}\right), 610$ $\left(1.79 \times 10^{2}\right), 678\left(3.25 \times 10^{4}\right) \mathrm{nm} ;{ }^{1} \mathrm{H}$ NMR $(400 \mathrm{MHz}$, $\left.\mathrm{CDCl}_{3}\right) \delta:-1.98($ br s, $1 \mathrm{H}, \mathrm{NH}), 0.03($ br s, $1 \mathrm{H}, \mathrm{NH}$ ), $1.74\left(\mathrm{t}, J=7.6 \mathrm{~Hz}, 3 \mathrm{H}, 8-\mathrm{CH}_{3}\right), 1.84(\mathrm{~d}, J=7.2 \mathrm{~Hz}, 3 \mathrm{H}$, $\left.18-\mathrm{CH}_{3}\right), 2.20 \sim 2.36(\mathrm{~m}, 1 \mathrm{H}, 17 \mathrm{a}+17 \mathrm{~b}-\mathrm{H}), 2.56 \sim 2.64$ (m, 2H, 17a+17b-H), 2.66 2.78 (m, 1H, 17a+17b-H), $3.25,3.54,3.62,3.72$ (each s, each $3 \mathrm{H}, \mathrm{CH}_{3}+\mathrm{OCH}_{3}$ ), 3.73 (q, $\left.J=7.6 \mathrm{~Hz}, 2 \mathrm{H}, 8 \mathrm{a}-\mathrm{CH}_{2}\right), 4.38(\mathrm{~d}, J=8.4 \mathrm{~Hz}, 1 \mathrm{H}, 17-\mathrm{H})$, 4.57 (q, $J=7.2 \mathrm{~Hz}, 1 \mathrm{H}, 18-\mathrm{H}), 5.18$ (d, $J=19.8 \mathrm{~Hz}, 1 \mathrm{H}$, $\left.13^{2}-\mathrm{H}\right), 5.34\left(\mathrm{~d}, J=19.8 \mathrm{~Hz}, 1 \mathrm{H}, 13^{2}-\mathrm{H}\right), 6.35(\mathrm{dd}, J=$ $10.6,1.0 \mathrm{~Hz}, 1 \mathrm{H}$, cis-3c-H), 6.54 (dd, $J=17.0,1.0 \mathrm{~Hz}, 1 \mathrm{H}$, trans-3c-H), 7.47 (dd, $J=17.0,10.6 \mathrm{~Hz}, 1 \mathrm{H}, 3 \mathrm{~b}-\mathrm{H}), 8.77$, 9.64, 9.65 (each s, each 1H, meso-H); IR (KBr) v: 3419 $(\mathrm{N}-\mathrm{H}), 2940,2917(\mathrm{C}-\mathrm{H}), 1738,1686 \quad(\mathrm{C}=\mathrm{O}), 1669$ $(\mathrm{C}=\mathrm{C}), 1526$ (chlorin skeleton), 1424, 1388, 1252, 1174, $999 \mathrm{~cm}^{-1}$; EI-MS m/z: $577.4\left(\mathrm{M}+\mathrm{H}^{+}\right)$. Anal. calcd for $\mathrm{C}_{35} \mathrm{H}_{36} \mathrm{~N}_{4} \mathrm{O}_{4}$ : C 72.90, H 6.29, N 9.72; found C 73.04, H $6.44, \mathrm{~N} 9.89$.

\section{$3.1112 \mathrm{a}(R / S)$-12-(1-羟乙基)-12-去甲基焦脱镁叶绿} 酸-a 甲酯(16)的合成

以二氢卟吩醛 $9 b$ 替代 $\mathrm{MPb}(\mathbf{1 b})$, 按照制备化合物 8 的方法合成. 得绿色固体 16, 产率 57\%. m.p. 226 $229{ }^{\circ} \mathrm{C}$; UV-Vis $\left(\mathrm{CHCl}_{3}\right) \lambda_{\max }\left[\varepsilon /\left(\mathrm{L} \cdot \mathrm{mol}^{-1} \cdot \mathrm{cm}^{-1}\right)\right]: 413$ $\left(1.16 \times 10^{5}\right), \quad 510 \quad\left(1.27 \times 10^{4}\right), \quad 524 \quad\left(8.67 \times 10^{2}\right), \quad 609$ $\left(6.11 \times 10^{3}\right), 666\left(5.12 \times 10^{4}\right) \mathrm{nm} ;{ }^{1} \mathrm{H}$ NMR $(400 \mathrm{MHz}$, $\left.\mathrm{CDCl}_{3}\right) \delta:-1.26(-1.27)($ br s, $1 \mathrm{H}, \mathrm{NH}), 0.70($ br s, $1 \mathrm{H}$, $\mathrm{NH}), 1.65$ (1.64) (t, $\left.J=7.6 \mathrm{~Hz}, 3 \mathrm{H}, 8-\mathrm{CH}_{3}\right), 1.80$ (1.78) (d, $\left.J=7.2 \mathrm{~Hz}, 3 \mathrm{H}, 18-\mathrm{CH}_{3}\right), 2.14(2.01)(\mathrm{d}, J=6.6 \mathrm{~Hz}, 3 \mathrm{H}$, 
$\left.12 \mathrm{a}-\mathrm{CH}_{3}\right), 2.23 \sim 2.27(\mathrm{~m}, 2 \mathrm{H}, 17 \mathrm{a}+17 \mathrm{~b}-\mathrm{H}), 2.51 \sim 2.73$ $(\mathrm{m}, 1 \mathrm{H}, 17 \mathrm{a}+17 \mathrm{~b}-\mathrm{H}), 3.15,3.35,3.63$ (each $\mathrm{s}$, each $3 \mathrm{H}$, $\mathrm{CH}_{3}+\mathrm{OCH}_{3}$ ), 3.60 (3.58) (q, $J=7.6 \mathrm{~Hz}, 2 \mathrm{H}, 8 \mathrm{a}-\mathrm{CH}_{2}$ ), $4.24(\mathrm{~d}, J=7.2 \mathrm{~Hz}, 1 \mathrm{H}, 17-\mathrm{H}), 4.42$ (q, $J=7.2 \mathrm{~Hz}, 1 \mathrm{H}$, 18-H), 4.87 (br s, 1H, 12-OH), 6.15 (d, $J=11.6 \mathrm{~Hz}, 1 \mathrm{H}$, cis-12b-H), 6.24 (d, J=17.8 Hz, 1H, trans-3b-H), $6.42(\mathrm{t}$, $J=6.6 \mathrm{~Hz}, 1 \mathrm{H}, 12 \mathrm{a}-\mathrm{H}), 7.91(\mathrm{dd}, J=17.8,11.6 \mathrm{~Hz}, 1 \mathrm{H}$, 3a-H), 8.45, 9.19, 9.35 (9.33) (each s, each 1H, meso-H ); IR (KBr) v: $3418(\mathrm{~N}-\mathrm{H}), 2846(\mathrm{C}-\mathrm{H}), 1719,1698(\mathrm{C}=$ O), $1600(\mathrm{C}=\mathrm{C}), 1500$ (chlorin skeleton), 1432, 1393, 1252, 1158, 1080, $893 \mathrm{~cm}^{-1}$; EI-MS m/z: $579.4\left(\mathrm{M}+\mathrm{H}^{+}\right)$. Anal. calcd for $\mathrm{C}_{35} \mathrm{H}_{38} \mathrm{~N}_{4} \mathrm{O}_{4}$ : C 72.64, $\mathrm{H}$ 6.62, N 9.68; found C 76.51, H 6.84, N 9.87.

\subsection{2-乙烯基-12-去甲基焦脱镁叶绿酸-a 甲酯(17) 的合成}

将 $124 \mathrm{mg} 16$ (0.214 mmol)溶解于 $15 \mathrm{~mL}$ 干燥的甲 苯中, 加入 $3 \mathrm{mg}$ 对甲苯磺酸, 氮气保护, $90{ }^{\circ} \mathrm{C}$ 搅拌反应 $0.5 \mathrm{~h}$, 先后加入 $20 \mathrm{~mL}$ 水和 $20 \mathrm{~mL}$ 二氯甲烷, 分出有机 层, 水层用二氯甲烷萃取 $(15 \mathrm{~mL} \times 3)$, 合并有机层并用 无水硫酸钠干燥, 除去溶剂, 剩余物经硅胶柱层析分离 [洗脱剂: $V$ (乙酸乙酯) $: V$ (正己烷 $)=1: 4$ ], 得到 $82 \mathrm{mg}$ 绿色固体 17 (0.146 mmol), 产率为 68\%. m.p. 186 $189{ }^{\circ} \mathrm{C}$; UV-Vis $\left(\mathrm{CHCl}_{3}\right) \lambda_{\max }\left[\varepsilon /\left(\mathrm{L} \cdot \mathrm{mol}^{-1} \cdot \mathrm{cm}^{-1}\right)\right]: 404$ $\left(1.21 \times 10^{5}\right), \quad 418\left(8.29 \times 10^{3}\right), \quad 556\left(7.96 \times 10^{2}\right), \quad 609$ $\left(6.11 \times 10^{3}\right), 682\left(6.12 \times 10^{4}\right) \mathrm{nm} ;{ }^{1} \mathrm{H}$ NMR $(400 \mathrm{MHz}$, $\left.\mathrm{CDCl}_{3}\right) \delta:-1.07$ (br s, $\left.1 \mathrm{H}, \mathrm{NH}\right),-0.12$ (br s, $1 \mathrm{H}, \mathrm{NH}$ ), 1.67 (t, $\left.J=7.6 \mathrm{~Hz}, 3 \mathrm{H}, 8-\mathrm{CH}_{3}\right), 1.79(\mathrm{~d}, J=7.2 \mathrm{~Hz}, 3 \mathrm{H}$, $\left.18-\mathrm{CH}_{3}\right), 2.14$ (2.01) (d, $\left.J=6.6 \mathrm{~Hz}, 3 \mathrm{H}, 12 \mathrm{a}-\mathrm{CH}_{3}\right), 2.25 \sim$ $2.36(\mathrm{~m}, 2 \mathrm{H}, 17 \mathrm{a}+17 \mathrm{~b}-\mathrm{H}), 2.52 \sim 2.59(\mathrm{~m}, 1 \mathrm{H}, 17 \mathrm{a}+$ 17b-H), $2.64 \sim 2.71(\mathrm{~m}, 1 \mathrm{H}, 17 \mathrm{a}+17 \mathrm{~b}-\mathrm{H}), 3.18,3.35,3.62$ (each s, each $\left.3 \mathrm{H}, \mathrm{CH}_{3}+\mathrm{OCH}_{3}\right), 3.67(\mathrm{q}, J=7.6 \mathrm{~Hz}, 2 \mathrm{H}$, $\left.8 \mathrm{a}-\mathrm{CH}_{2}\right), 4.23$ (d, $\left.J=8.2 \mathrm{~Hz}, 1 \mathrm{H}, 17-\mathrm{H}\right), 4.41$ (q, $J=7.2$ $\mathrm{Hz}, 1 \mathrm{H}, 18-\mathrm{H}$ ), 5.09 (d, $\left.J=19.6 \mathrm{~Hz}, 1 \mathrm{H}, 13^{2}-\mathrm{H}\right), 5.24$ (d, $\left.J=19.6 \mathrm{~Hz}, 1 \mathrm{H}, 13^{2}-\mathrm{H}\right), 6.16(\mathrm{~d}, J=11.6 \mathrm{~Hz}, 2 \mathrm{H}, c i s-3 \mathrm{~b}+$ 12b-H), 6.24 (d, $J=17.8 \mathrm{~Hz}, 1 \mathrm{H}$, trans $-3 \mathrm{~b}-\mathrm{H}), 7.62$ (d, $J=$ $17.2 \mathrm{~Hz}, 1 \mathrm{H}$, trans-12b-H), 7.92 (dd, $J=17.8,11.6 \mathrm{~Hz}, 1 \mathrm{H}$, $3 \mathrm{a}-\mathrm{H}), 8.21$ (dd, $J=17.2,11.0 \mathrm{~Hz}, 1 \mathrm{H}, 12 \mathrm{a}-\mathrm{H}), 8.42,9.21$, 9.49 (each s, each 1H, meso-H); IR (KBr) v: $3409(\mathrm{~N}-\mathrm{H})$, $2935(\mathrm{C}-\mathrm{H}), 1737,1694(\mathrm{C}=\mathrm{O}), 1605(\mathrm{C}=\mathrm{C}), 1525$ (chlorin skeleton), 1385, 1256, 1166, 1077, 892, $778 \mathrm{~cm}^{-1}$; EI-MS $m / z$ : $561.4\left(\mathrm{M}+\mathrm{H}^{+}\right)$. Anal. calcd for $\mathrm{C}_{35} \mathrm{H}_{36} \mathrm{~N}_{4} \mathrm{O}_{3}$ : C 74.98, H 6.47, N 9.99; found C 75.11, H 6.64, N 10.17.

\subsection{3 体外光动力抗菌活性的测定}

待测样品和对照品: 分别选择化合物 1a、3、5、7、 10 13 和 17 为待测化合物, 选择临床药物青霉素钠为
对照品, 将样品和对照分别溶于 DMSO 和水配置成 10 $\mathrm{mmol} \cdot \mathrm{L}^{-1}$ 的母液待用.

菌体培养及 PDT 抑菌测定：将冻存菌种熔化后接 入营养肉汤培养基, $37{ }^{\circ} \mathrm{C}$ 摇床培养 $24 \mathrm{~h}$. 再分别适量移 接至新鲜培养基中, $37{ }^{\circ} \mathrm{C}$ 振荡培养直至对数生长后期, 该菌悬液以 $1: 100 \sim 1 ： 50$ 的比例接种于 $100 \mathrm{~mL} \mathrm{LB}$ 液 体培养基中, $37{ }^{\circ} \mathrm{C}$ 振荡培养至 $\mathrm{OD}_{600}=0.5$, 采用分光光 度计测定，将试验菌用液体培养基稀释至所需浓度. 用 微量加样器分别取 $5 \mu \mathrm{L}$ 试验菌稀释液, 放入待测样品 及对照品两个系列梯度液试管中，一个迅速置于暗处； 另一个用 BioSpec LED $(670 \sim 700 \mathrm{~nm})$ 作为光源距 $20 \mathrm{~cm}$ 照射 $30 \mathrm{~min}\left(2.0 \mathrm{~J} / \mathrm{cm}^{2}\right)$. 用微量加样器分别从试管中取 $5 \mu \mathrm{L}$ 到制好的 LB 培养基培养基平血中，迅速均匀涂板， 然后倒置于 $(36 \pm 1){ }^{\circ} \mathrm{C}$ 培养箱中, $(24 \pm 2) \mathrm{h}$ 后取出并进 行菌落计数并绘制菌落群-样品浓度曲线.

\section{References}

[1] Scheer, H. In Chlorophylls and Bacteriochlorophylls: Biochemistry, Biophysics, Functions and Applications, Vol. 1, Eds.: Grimm, B.; Porra, R. J.; Rüdiger, W.; Scheer, H, Springer, 2006, p. 1.

[2] Tsuchiya, T.; Mizoguchi, T.; Akimoto, S.; Tomo, T.; Tamiaki, H.; Mimuro, M. Plant Cell Physiol. 2012, 53(3), 518.

[3] (a) Hoober, J. K.; Eggink, L. L.; Chen, M. Photosynth. Res. 2007, 94, 387.

(b) Mizoguchi, T.; Shoji, A.; Kunieda, M.; Miyashita, H.; Tsuchiya, T.; Mimuro, M.; Tamiaki, H. Photochem. Photobiol. Sci. 2006, 5, 291.

[4] (a) Wang, J.-J. Chin. J. Org. Chem. 2005, 25, 1353 (in Chinese). (王进军, 有机化学, 2005, 25, 1353.)

(b) Xu, X.-S.; Yao, N-N.; Liu, Y.; Yin, J.-G.; Qi, C.-X.; Wang, J.-J. Chin. J. Org. Chem. 2014, 34, 938 (in Chinese)

(徐希森, 姚楠楠, 刘洋, 殷军港, 祁彩霞, 王进军, 有机化学, 2014, 34, 938.)

[5] (c) Liu, Y.; Xu, X.-S.; Li, J.-Z.; Yin, J.-G.; Qi, C.-X.; Wang, J.-J. Chin. J. Org. Chem. 2014, 34, 552 ( in Chinese).

(刘洋, 徐希森, 李家柱, 殷军港, 祁彩霞, 王进军, 有机化学, 2014, 34, 552.)

[6] (a) Chen, Y. H.; Li, G. L.; Pandey, R. K. Curr. Org. Chem. 2004, 8, 1105.

(b) Morishita, H.; Tamiaki, H. Tetrahedron 2005, 61, 6097.

[7] Ji, J.-Y.; Xia, C.-W.; Liu, Y.; Yin, J.-G.; Qi, C.-X.; Wang, J.-J. Chin. J. Org. Chem. 2014, 34, 1138 ( in Chinese).

(纪建业, 夏尚文, 刘洋, 殷军港, 祁彩霞, 王进军, 有机化学, 2014, 34, 1138.)

[8] (a) Bellnier, D. A.; Greco, W. R.; Loewen, G. M.; Nava, H.; Oseroff, A. R.; Pandey, R. K.; Tsuchida, T.; Dougherty, T. J. Cancer Res. 2003, 63.

(b) Wang, J.-J.; Li, J.-Z.; Li, Y.-W.; Jakus, J.; Shim, Y.-K. J. Porphyrins Phthalocyanines 2010, 14, 859.

(c) Wang, J.-J.; Li, J.-Z.; Jakus. J.; Shim, Y. K. J. Porphyrins Phthalocyanines 2012, 16, 122

[9] Ethirajan, M.; Chen, Y.-H.; Joshi, P.; Pandey, R. K. Chem. Soc. Rev. 2011, 40, 340

[10] Kozyrev, R. K.; Chen, Y.-H.; Goswami, L. N.; Tabaczynski, W. A.; Pandey, R. K. J. Org. Chem. 2006, 71.1949

[11] Li, J.-Z.; Zhang, P.; Zhang, S.-G.; Yin, J.-G.; Wang, J.-J. Org. Biol. 
Chem. 2015, 13, 1992.

[12] (a) Wainwringht, M.; Phoenix, D. A.; Marland, J. FEMS Immunol. Med. Microbiol. 1997, 19(1), 75.

(b) Wilson, M.; Burns, T.; Pratten, J. J. Appl. Bacteriol. 1995, 78, 569.

[13] Smith, K. M.; Gogg, D. A.; Simpson, D. J. J. Am. Chem. Soc. 1985, $107,4946$.

[14] Wu, J.; Yin, J.-G.; Zhang, Q.; Sun, C.-M.; Li, F.-G.; Pei, W.; Wang,
J.-J. Chin. J. Org. Chem. 2011, 31, 1653 ( in Chinese).

(武进, 殷军港, 张千, 孙传民, 李付国, 裴文, 王进军, 有机化 学, 2011, 31, 1653.)

[15] Yin, J.-G.; Wang, Z.; Yang, Z.; Liu, C.; Zhao, L.-L.; Wang, J.-J. Chin. J. Org. Chem. 2012, 32, 360 ( in Chinese).

(殷军港, 王振, 杨泽, 刘超, 赵丽丽, 王进军, 有机化学, 2012, 32, 360.)

(Li, L.; Fan, Y.) 